\title{
Tuberous sclerosis complex with oral manifestations: A case report and literature review
}

\author{
Karmen Harutunian ${ }^{1}$, Rui Figueiredo ${ }^{2}$, Cosme Gay-Escoda ${ }^{3}$
}

\begin{abstract}
${ }^{1}$ DDS. Resident of the Master of Oral Surgery and Implantology. Barcelona University Dental School
${ }^{2}$ DDS. Master in Oral Surgery and Implantology. Associate professor of Oral Surgery. Professor of the Master of Oral Surgery and Implantology. Barcelona University Dental School. Reseacher of the IDIBELL Institute

${ }^{3} \mathrm{MD}$, DDS, PhD. Chairman of Oral and Maxillofacial Surgery. Director of the Master of Oral Surgery and Implantology. University of Barcelona Dental School. Coordinating reseacher of the IDIBELL Institute. Head of the Service of Maxillofacial Surgery, Teknon Medical Center. Barcelona, Spain
\end{abstract}

Correspondence:

Centro Médico Teknon,

Instituto de investigación IDIBELL,

C/ Vilana 12

08022 Barcelona (Spain)

cgay@ub.edu

\author{
Harutunian K, Figueiredo R, Gay-Escoda C. Tuberous sclerosis complex \\ with oral manifestations: A case report and literature review. Med Oral \\ Patol Oral Cir Bucal. 2011 Jul 1;16 (4):e478-81. \\ http://www.medicinaoral.com/medoralfree01/v16i4/medoralv16i4p478.pdf \\ Article Number: 16860 http://www.medicinaoral.com/ \\ (C) Medicina Oral S. L. C.I.F. B 96689336 - pISSN 1698-4447 - eISSN: 1698-6946 \\ eMail: medicina@medicinaoral.com \\ Indexed in: \\ Science Citation Index Expanded \\ Journal Citation Reports \\ Index Medicus, MEDLINE, PubMed \\ Scopus, Embase and Emcare \\ Indice Médico Español
}

Received: $22 / 02 / 2010$

Accepted: 31/05/2010

\begin{abstract}
Introduction: Tuberous sclerosis complex (TSC) is a neurocutaneous syndrome produced by a number of genetic mutations. The disease is characterized by the development of benign tumors affecting different body systems. The most common oral manifestations of TSC are fibromas, gingival hyperplasia and enamel hypoplasia.

Clinical Case: A 35-year-old woman diagnosed with TSC presented with a reactive fibroma of considerable size and rapid growth in the region of the right lower third molar.

Discussion: In the present case the association of TSC with dental malpositioning gave rise to a rapidly evolving reactive fibroma of considerable diameter. Few similar cases can be found in the literature. Patients with TSC present mutations of the TSC1 and TSC2 genes, which intervene in cell cycle regulation and are important for avoiding neoplastic processes. No studies have been found associating TSC with an increased risk of oral cancer, though it has been shown that the over-expression of TSC2 could exert an antitumor effect. Careful oral and dental hygiene, together with regular visits to the dentist, are needed for the prevention and early detection of any type of oral lesion. The renal, pulmonary and cardiac alterations often seen in TSC must be taken into account for the correct management of these patients.
\end{abstract}

Key words: Tuberous sclerosis, reactive fibroma, oral manifestations. 


\section{Introduction}

Tuberous sclerosis complex (TSC) is a neurocutaneous syndrome characterized by the development of benign tumors such as neurofibromas and angiofibromas located anywhere in the body (skin, central nervous system, heart, kidneys, etc.).

Patients with TSC present mutations of the TSC1 and TSC2 genes, which intervene in cell cycle regulation. This is a dominant autosomal hereditary disease, though $60-70 \%$ of all cases are the result of spontaneous mutations $(1,2)$. The prevalence of TSC ranges from 1:6,000 to $1: 10,000$ individuals, and the diagnosis is usually established between 4-10 years of age or in puberty (3).

TSC manifests with variable signs and symptoms together with angiofibromas distributed in a characteristic "butterfly" pattern on the face and forehead. The most important neurological problems are mental retardation, seizures, autism and learning difficulties. The diagnostic criteria of TSC have been divided into major and minor features (Table 1). The presence of two major characteristics or of one major criterion and two minor criteria confirms the diagnosis. A molecular diagnosis is advised in patients at risk, in order to diagnose the disease before the actual symptoms appear $(1,3,4)$.

The cerebral manifestations and renal complications of TSC exert an important influence upon patient prognosis (4).

The most common oral manifestations of TSC are fibromas, gingival hyperplasia and enamel hypoplasia (5). Other less frequent findings in the oral cavity are a high arched palate, bifid uvula, harelip and/or cleft palate, delayed dental eruption and the presence of diastemas (6).

Table 1. Diagnostic criteria of tuberous sclerosis complex (TSC).

\begin{tabular}{|cl|}
\hline Major criteria \\
- & Facial angiofibromas \\
- & Multiple ungual fibromas (Koenen tumors) \\
- & Cortical tubercle \\
- & Subependymal nodule \\
- & Multiple astrocytomas \\
- & Renal angiolipomas \\
- & Hypomelanocytic maculae (3 or more) \\
- & Cardiorhabdomyomas \\
\hline & \\
Minor criteria \\
- & Cerebral tubercles \\
- & Non-calcified subependymal nodules \\
- & Hamartomatous rectal polyps \\
- & Gingival fibromas \\
- & Non-renal hamartomas \\
- & Multiple renal cysts \\
- & Retinal hamartomas \\
- & Enamel hypoplasia \\
\hline
\end{tabular}

\section{Clinical Case}

A 35-year-old woman was seen in the Service of Oral Surgery (Dental Clinic of the University of Barcelona, Spain) in March 2009 for the evaluation of continuous, intense pain for the past two days, located in the right hemimandibular region. The patient explained that she noticed the appearance of an asymptomatic mass in the right lower third molar region a few months ago, and that the lesion had gradually grown since then.

TSC had been diagnosed at age 23 years as a result of the presence of Koenen tumors on the face, fingers and toes, lumbar connective tissue nevus, parascapular hypomelanocytic macula, and enamel hypoplasia of the left upper central incisor. Magnetic resonance imaging, funduscopy and abdominal ultrasound were also performed, revealing the presence of renal alterations. In 1999 the patient underwent kidney transplantation due to chronic renal failure secondary to angiomyolipomas, and two years later bilateral breast fibroadenomas were removed and a simple total hysterectomy was performed due to multiple uterine fibromatosis. On several occasions she underwent surgery for the removal of Koenen tumors, angiofibromas and epidermoid cysts in the facial region. Posteriorly, in 2005, right and left radical nephrectomy was carried out.

At the time of her visit to our Service, the patient was taking the following medication: $5 \mathrm{mg}$ of glucocorticoids daily via the oral route (Dacortin ${ }^{\circledR} 5 \mathrm{mg}$; Merck, Madrid, Spain), $250 \mathrm{mg}$ of cyclosporine daily via the oral route (Sandimmun neural ${ }^{\circledR} 50 \mathrm{mg}$; Novartis, Barcelona, Spain), and $20 \mathrm{mg}$ of enalapril maleate daily via the oral route (Renitec ${ }^{\circledR} 5 \mathrm{mg}$; Merck, Madrid, Spain).

Oral and dental exploration revealed the presence of a papillomatous tumor of the same color as the oral mucosa and measuring $2.5 \mathrm{~cm}$ in diameter, enveloping the right lower third molar, which in turn showed grade 3 mobility (Fig. 1A). A lesion of similar characteristics but smaller size $(1 \mathrm{~cm})$ was identified in association to the root fragments of the left lower third molar (Fig. 1B). The lesions were asymptomatic, but percussion of the right lower third molar caused pain.

A panoramic radiography and a computed tomography scan of the mandible and upper maxilla (Fig. 2A-B) showed well defined radiotransparencies with regular margins in the region of the lower third molars. The lower third molars were removed and the associated lesions were resected. The histopathological study of the tumor tissue confirmed the presence of reactive fibroma (Fig. 3A-B). 


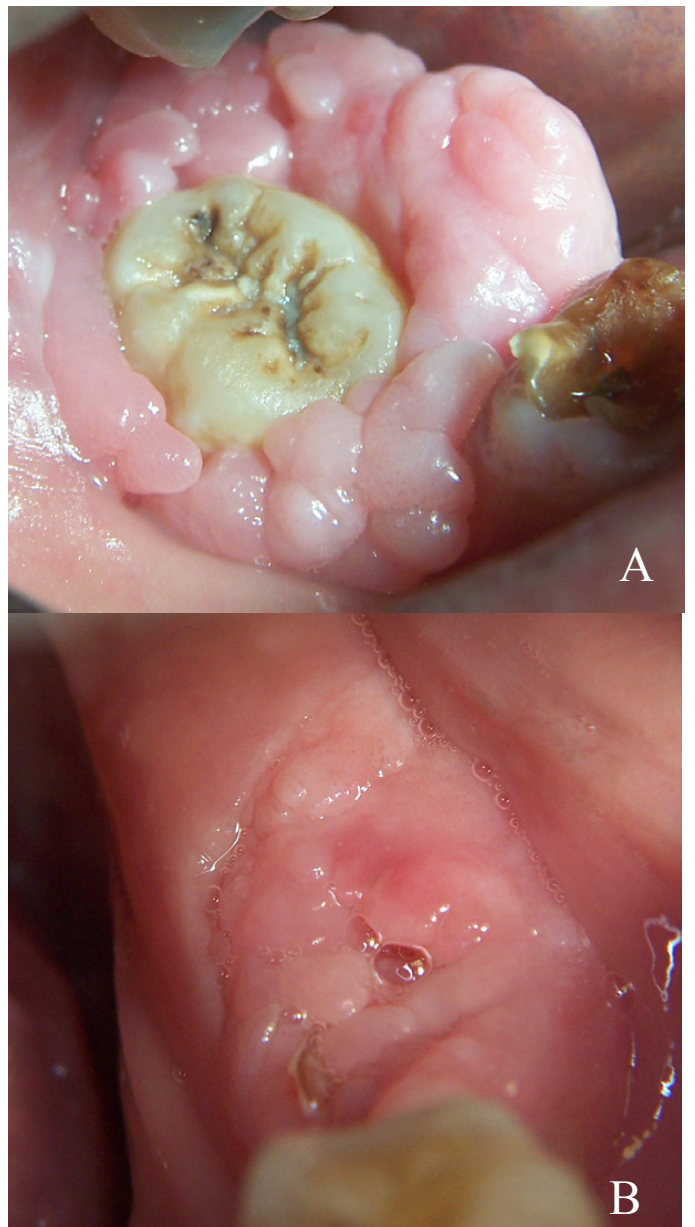

Fig. 1. Clinical examination. A. Lesion associated to the right lower third molar. B. Lesion related to the root remains of the left lower third molar.
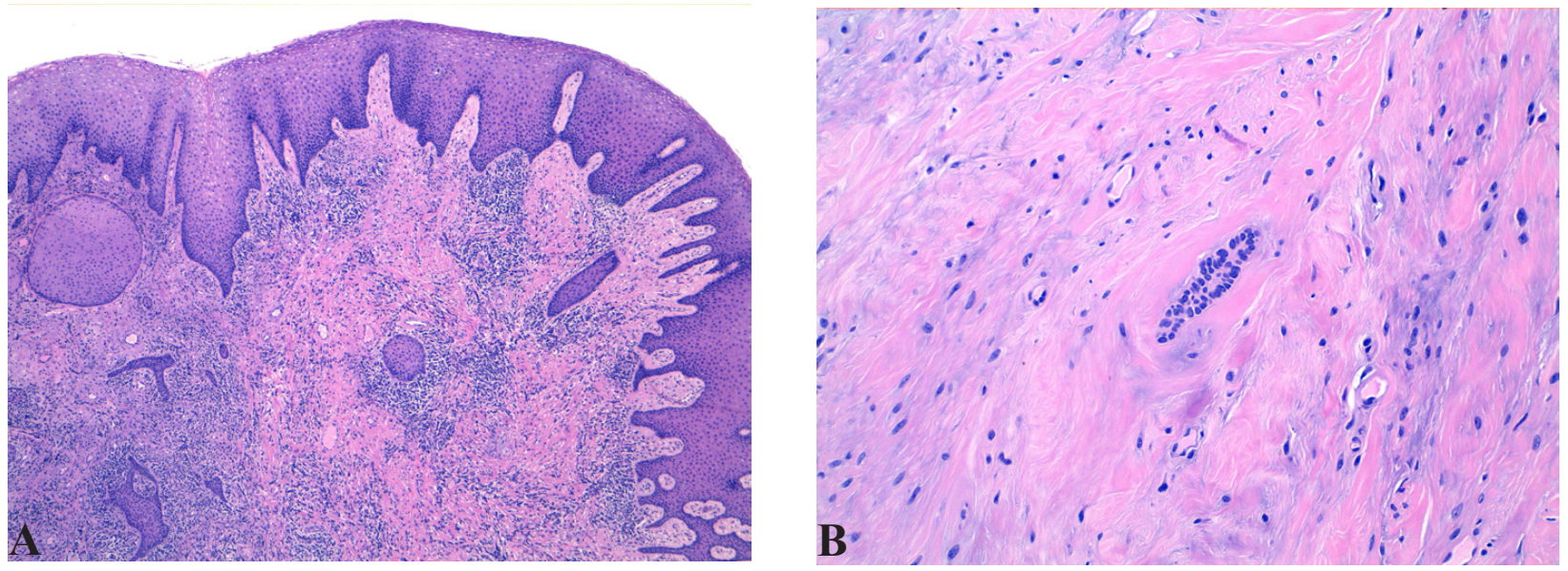

Fig. 3. Histological study (hematoxylin-eosin stain). A. Chronic inflammation with epithelial hyperplasia is observed (x100). B. Collagencontaining fibrous tissue fragments are seen, with few cells, enveloping remains of odontogenic epithelium (x200). 


\section{Discussion}

Tuberous sclerosis complex (TSC) is often associated with mental retardation (in 70\% of cases) and epilepsy $(90 \%)$. Koenen tumors and angiofibromas in turn are observed in $15-20 \%$ and $70 \%$ of all cases, respectively. Renal angiomyolipomas and cysts affect one-half of patients with TSC and are the cause of chronic renal failure that may prove fatal. Cardiac rhabdomyomas are normally observed before age 25 years in $30-50 \%$ of all cases, and are also a cause of early death $(4,7)$. Our patient presented Koenen tumors, renal oncocytomas and angiomyolipomas, angiofibromas and enamel hypoplasia, but no mental retardation or epilepsy.

The most common oral manifestations of TSC are fibrous hyperplasias and enamel hypoplasia (7). The former are more often found in the gingival zones of the anterior sector, though involvement of the lips, tongue and palate is not unusual. According to some authors, these hyperplasias may be secondary to the medication usually taken by these patients (8). The incidence of oral fibromas in TSC varies according to the different literature sources between 50-69\%, with an average diameter of $5 \mathrm{~mm}$ (9-12). The aggressivity of the lesions depends on the severity of the local factors. Our patient presented a rapidly evolving reactive fibroma measuring $2.5 \mathrm{~cm}$ in diameter, associated to a malpositioned lower third molar. The literature offers no evidence of similar oral fibromas.

It should be noted that these patients present mutations of the TSC1 and TSC2 genes. These genes intervene in cell cycle regulation and are important for avoiding neoplastic processes (13). No studies have been found associating TSC with an increased risk of oral cancer, though according to Kawaguchi et al. (14), TSC2 overexpression could exert an antitumor effect in oral cancer, since it is an oncosuppressor gene. Fleury et al. (15) published a case of undifferentiated pleomorphic sarcoma located in the mandible of a patient with TSC.

Enamel hypoplasia is present in the permanent dentition of almost $100 \%$ of these patients, and is associated with an increased risk of caries. This anomaly typically affects the vestibular surfaces of several teeth. No specific studies have been published on the oral hard tissue manifestations of TSC. According to Barron et al. (16), mesenchymal tumors such as myxoma, desmoplastic fibroma and odontogenic fibroma can be found in the maxillas of patients diagnosed with this disease. A correct differential diagnosis of these lesions must be established in order to apply adequate treatment $(15,16)$. Patients with TSC must adopt measures for careful oral and dental hygiene, with regular visits to the dentist, in order to eliminate potential irritative factors and ensure the early diagnosis of any possible lesions. The oral healthcare professional in turn must always request a detailed medical report on the condition of the patient.
Due to the frequent renal, cardiac and pulmonary alterations, general anesthesia, intravenous sedation and pre- and postoperative medication must be administered with caution.

References with links to Crossref - DOI

\section{References}

1. Hung CC, Su YN, Chien SC, Liou HH, Chen CC, Chen PC, et al. Molecular and clinical analyses of 84 patients with tuberous sclerosis complex. BMC Med Genet. 2006;7:72.

2. Inoki K, Guan KL. Tuberous sclerosis complex, implication from a rare genetic disease to common cancer treatment. Hum Mol Genet. 2009;18:R94-100.

3. Cutando A, Gil JA, López J. Oral health management implications in patients with tuberous sclerosis. Oral Surg Oral Med Oral Pathol Oral Radiol Endod. 2000;90:430-5.

4. Schwartz RA, Fernández G, Kotulska K, Jóźwiak S. Tuberous sclerosis complex: advances in diagnosis, genetics, and management. J Am Acad Dermatol. 2007;57:189-202.

5. Korol UB, Schoor R, Nanda V, Almas K, Phelan JA. Gingival enlargement as a manifestation of tuberous sclerosis: case report and periodontal management. J Periodontol. 2008;79:759-63.

6. Fahsold R, Rott HD, Lorenz P. A third gene locus for tuberous sclerosis is closely linked to the phenylalanine hydroxylase gene locus. Hum Genet. 1991;88:85-90.

7. Gupta S, Bhowate R, Degwekar SS. Clinical and radiological findings related to tuberous sclerosis complex: a case report. J Contemp Dent Pract. 2008;9:85-91.

8. López E, Escovich L, Vigna A. Tuberous sclerosis: presentation of a clinical case with oral manifestations. Med Oral. 2003;8:122-8.

9. Lygidakis NA, Lindenbaum RH. Oral fibromatosis in tuberous sclerosis. Oral Surg Oral Med Oral Pathol. 1989;68:725-8.

10. Sparling JD, Hong CH, Brahim JS, Moss J, Darling TN. Oral findings in 58 adults with tuberous sclerosis complex. J Am Acad Dermatol. 2007;56:786-90.

11. Alvarez Alvarez C, Fernández Sanromán J, Fernández Castilla M, Antón Badiola I. Sporadic oral angiomyolipoma. Case report. Med Oral Patol Oral Cir Bucal. 2007;12:E391-3.

12. Da Silva AA, Carlos R, Contreras E, De Almeida OP, Lopes MA, Vargas PA. Angiomyolipoma of the upper lip: case report and review of the literature. Med Oral Patol Oral Cir Bucal. 2007;12:E101-4.

13. Chakraborty S, Mohiyuddin SM, Gopinath KS, Kumar A. Involvement of TSC genes and differential expression of other members of the mTOR signaling pathway in oral squamous cell carcinoma. BMC Cancer. 2008;8:163.

14. Kawaguchi S, Harada K, Supriatno, Yoshida H, Sato M. Overexpression of tuberous sclerosis complex 2 exerts antitumor effect on oral cancer cell lines. Oral Oncol. 2003;39:836-41.

15. Fleury RN, Damante JH, Soares CT, Sant'Ana E, Mello EJ Jr, Moreira CR. Malignant fibrous histiocytoma (undifferentiated high-grade pleomorphic sarcoma) occurring in tuberous sclerosis: a case report. Oral Surg Oral Med Oral Pathol Oral Radiol Endod. 2007;103:e54-9.

16. Barron RP, Kainulainen VT, Forrest CR, Krafchik B, Mock D, Sàndor GK. Tuberous sclerosis: clinicopathologic features and review of the literature. J Craniomaxillofac Surg. 2002;30:361-6. 